\title{
RECRUITMENT IN 1710-1711 AND DISTRIBUTION OF RECRUITS TO THE GARRISONS OF NORTHWESTERN RUSSIA
}

\author{
Nikolai R. Slavnitsky \\ State Museum of the History of Saint Petersburg, Saint Petersburg, Russian Federation
}

\begin{abstract}
Introduction. The article considers the issues related to the distribution of recruits among garrison regiments in the fortresses of northwestern Russia in 1711-1712. In Russian historiography, the history of recruitment has been repeatedly considered, although, researchers did not pay attention to the distribution of recruits among the regiments. Methods and materials. In the archives of various departments documents have been preserved that make it possible to identify some details of the direction of recruitment in 1710-1711. Most of the documents on the issue of interest to us are stored in the fund of the Office of A.D. Menshikov; important documents were also found in the archives of the Artillery and Naval Departments. Analysis. According to the data at our disposal, it was from 1711 that the practice of sending recruits to the garrison regiments began, where they underwent initial military training, and then were sent to units of the field army (and new recruits were sent to their places). The recruitments of 1711 were officially announced in connection with the war against Turkey and the Prut campaign of the Russian army. However, at the same time, there was a need to replenish garrison regiments of fortresses in the northwest of Russia, and the recruits began to be sent there. Apparently, the recruits of 1710 and the first recruitment of 1711 were used for this. At the same time, the garrisons of the Baltic fortresses (Riga and Revel) were formed from regiments fully staffed with recruits. Results. Initially, the principle of recruiting garrison regiments was established spontaneously, but later it was used, and documents found in the archives of the Artillery and Naval Departments, as well as in the fund of the Office of A.D. Menshikov, allow us to trace this.
\end{abstract}

Key words: Northern War, Peter I, recruitment, Senate, garrisons, R.V. Bruce.

Citation. Slavnitsky N.R. Recruitment in 1710-1711 and Distribution of Recruits to the Garrisons of Northwestern Russia. Vestnik Volgogradskogo gosudarstvennogo universiteta. Seriya 4. Istoriya. Regionovedenie. Mezhdunarodnye otnosheniya [Science Journal of Volgograd State University. History. Area Studies. International Relations], 2021, vol. 26, no. 1, pp. 33-40. (in Russian). DOI: https://doi.org/10.15688/jvolsu4.2021.1.4

\section{РЕКРУТСКИЕ НАБОРЫ 1710-1711 ГГ. И РАСПРЕДЕЛЕНИЕ РЕКРУТОВ В ГАРНИЗОНЫ СЕВЕРО-ЗАПАДА РОССИИ}

\author{
Николай Равильевич Славнитский \\ Государственный музей истории Санкт-Петербурга, г. Санкт-Петербург, Российская Федерация
}

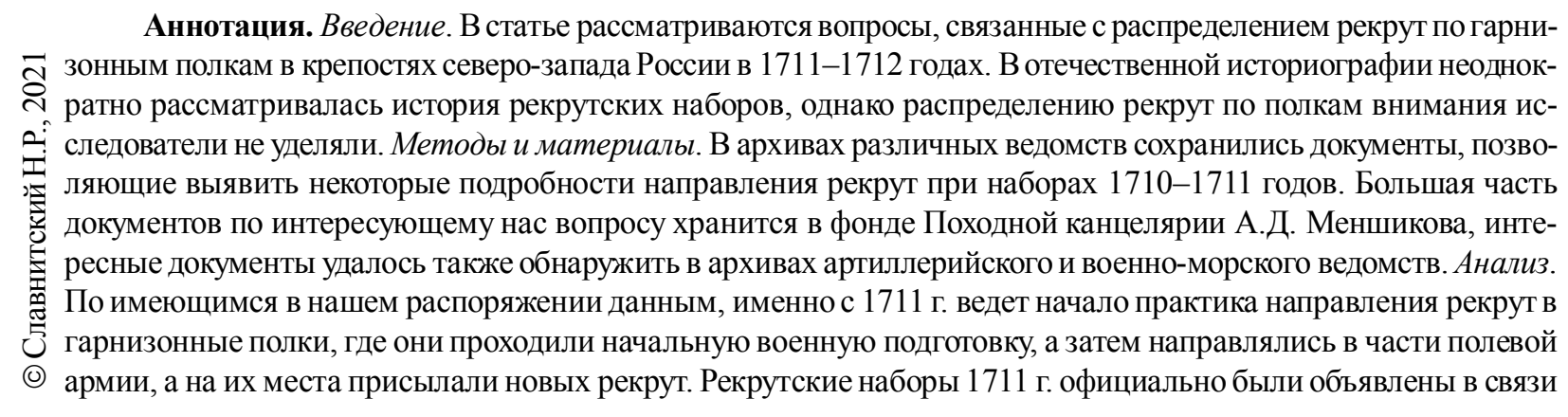


с войной против Турции и Прутским походом российской армии. Однако в это же время возникла необходимость пополнения гарнизонных полков крепостей северо-запада России, и рекрут стали направлять именно туда. Использовались для этого, по всей видимости, рекругы набора 1710 г. и первого набора 1711 года. Резульmaты. Первоначально принцип комплектования гарнизонных полков рекрутами сложился стихийно. Документы, обнаруженные в архивах артиллерийского и военно-морского ведомств, а также в фонде Походной канцелярии А.Д. Меншикова, позволили выяснить, что большую часть рекрут направили в гарнизоны Риги и Ревеля, а также в Санкт-Петербург и другие крепости Ингерманландии. В последующие годы пополнение гарнизонных полков за счет рекрут стало правилом.

Ключевые слова: Северная война, Петр I, рекругские наборы, Сенат, гарнизоны, Р.В. Брюс.

Цитирование. Славнитский Н. Р. Рекрутские наборы 1710-1711 гг. и распределение рекрутов в гарнизоны северо-запада России // Вестник Волгоградского государственного университета. Серия 4, История. Регионоведение. Международные отношения. - 2021. - Т. 26, № 1. - С. 33-40. - DOI: https://doi.org/10.15688/ jvolsu4.2021.1.4

Введение. Указом Петра I от 20 февраля 1705 г. был объявлен первый массовый рекрутский набор и тем самым окончательно утвердились новые принципы комплектования войск, просуществовавшие до 1870-х годов. История рекрутских наборов неоднократно рассматривалась исследователями. Еще в XIX в. очерк рекрутских наборов составил К.М. Поливанов [20], во второй половине XX столетия рекрутские наборы были затронуты в работах Л.Г. Бескровного [4] и Е.В. Анисимова [1], а из современных исследователей следует выделить В.А. Тихонова [24; 25]. Однако вопросы, связанные с распределением рекрут по воинским частям, в отечественной историографии практически не рассматривались.

Цель работы - установить, в какие именно части, расположенные в крепостях северо-запада, направляли рекрут в рассматриваемый период, с чем это было связано и с какими трудностями сталкивались коменданты и другие должностные лица.

Методы и материалы. Основная задача исследования - выяснить на основе документальных материалов, когда и каким образом рекрут стали направлять в гарнизонные полки. Материалов о распределении рекрут в первом десятилетии Северной войны нам пока обнаружить не удалось. В архивах различных ведомств сохранились документы, позволяющие выявить некоторые подробности направления рекрут при наборах 1710-1711 годов. Большая часть документов по интересующему нас вопросу хранится в фонде Походной канцелярии А.Д. Меншикова в Научно-историческом архиве Санкт-Петербургского Ин- ститута Истории РАН (Архив СПб ИИ РАН). Это донесения губернатору от комендантов крепостей, в которых содержатся сведения, в какие именно гарнизоны направляли рекрут. Именно из этих донесений и становится ясно, каким образом проходило распределение и с какими трудностями сталкивались при этом. Некоторые важные и интересные сведения удалось также обнаружить в архиве Приказа артиллерии (Архив Военно-исторического музея артиллерии, инженерных войск и войск связи), а также в архиве адмиралтейского ведомства (в Российском государственном архиве военно-морского флота). Данный комплекс документов при использовании системного подхода позволяет проследить, как распределяли рекрут в 1710-1711 годах.

Хронологические рамки статьи обусловлены двумя обстоятельствами. Во-первых, реформированием самой рекрутской системы - в марте 1711 г. был создан Сенат, и именно этот орган власти с того времени стал заниматься рекрутскими наборами. Во-вторых, именно в 1711-1712 гг. в крепостях северозапада появились постоянные полки, которые можно называть гарнизонными. В предыдущее десятилетие там находились полки, назначенные к обороне конкретного укрепленного пункта, и они, в принципе, могли меняться - эти части нередко перебрасывали с одного участка на другой, вместо них присылали другие полки. Это было вполне естественно в обстановке боевых действий, а вот после кампании 1710 г. уже появилась возможность более планомерно распределить гарнизонные полки по крепостям, и установить для них постоянные штаты (вообще именно в то 
время занялись серьезной разработкой полковых штатов).

Анализ. Рекрутским набором 1710 г. предусматривалось собрать в Ингерманландской губернии 2624 рекрута, в Казанской 1722 , в Сибирской - 738 и в Московской 3649 человек. Примечательно, что план этот Петр I составил лично. В.А.Тихонов справедливо считает, что данный факт является показателем того, что рекрутская система в то время находилась в полном беспорядке. Кроме того, царским распоряжением 18 августа 1710 г. предусматривалось набрать 1200 рекрут в гарнизоны Риги, Дюнаминда и Пернова [25, с. 34-35].

Это первый известный нам документ о направлении рекрут в гарнизонные части. И связан он был, очевидно, с чрезвычайной ситуацией - в Прибалтике в 1710 г. свирепствовала эпидемия, которая нанесла урон не только местному населению, но и российским частям, действовавшим там, и выделить необходимое число солдат и офицеров из действующей армии было проблематично.

В 1711 г. было объявлено два рекрутских набора, и оба были официально связаны с Прутским походом. Указом Сената 16 марта 1711 г. повелевалось: «для нынешнего настоящего воинского случая собрать со всех губерний в запас рекрутов вновь 25000 человек, да 7000 лошадей в драгунскую службу годных бессрочно» [21, с. 649]. А в соответствии с сенатским указом от 30 июня 1711 г. требовалось набрать со всех губерний, кроме Санкт-Петербургской, 20000 человек и 7000 лошадей [21, с. 707].

Санкт-Петербургская губерния была освобождена от набора по донесению А.Д. Меншикова, который сообщил, что область обезлюдела из-за эпидемии предыдущего года и, кроме того, ее постоянно тревожили неприятельские отряды [21, с. 707]. И то, и другое соответствовало действительности. Окрестности Санкт-Петербурга тревожили шведские «партизаны» [3], а эпидемия 1710-1711 гг. затронула не только жителей, но и те воинские части, которые находились в Ингерманландии. По данным М.В. Бабич и И.В. Бабич, в этот период в полках умерло 6535 человек [2].

В.А. Тихонов в одной из своих работ обратил внимание на рекрутский набор 1711 г., проводившийся в Санкт-Петербургской губернии специально для формирования местной ланд-милиции [24]. Кроме того, он же выяснил, что 31 августа А.Д. Меншиков запросил у Сената 200 рекрут для пополнения Адмиралтейского батальона. Это подтверждается документальными материалами в фонде Адмиралтейств-коллегии. В октябре 1712 г. среди получивших жалованье мастеров, подмастерьев, мастеровых и иных чинов из разных губерний переведенцев за работы в Санкт-Петербурге указаны 26 человек «из рекрут». Еще 5 рекрут в то время находились «у шлюпочного дела» и 12 человек - у «досочного дела» $[5$, л. $30,55,57]$. Скорее всего, эти рекруты первоначально были определены в Адмиралтейский батальон, а затем их стали использовать в качестве рабочих.

Но такая форма использования рекрут являлась все же исключением, большинство оказывалось в полках. Имеющиеся в нашем распоряжении документы позволяют уточнить, каким образом распределяли тех рекрут, что были набраны в те годы.

В первую очередь приведем донесение А.Д. Меншикову санкт-петербургского оберкоменданта Р.В. Брюса, который 21 февраля 1711 г. сообщил губернатору: «По отъезде вашего светлешейства рекрут для дополнения полков к нам ни единого человека не бывало. А которые 204 человека в бытность вашу от господина архитектора приняты и отданы в полки, тех ныне при походах учат стрельбою...» $[10$, л. 1]. 5 марта он же сообщил, что рекрут по-прежнему не имеется, «також о новых полках, которых сюды ожидаем, ведомости никакой не имеем» $[11$, л. 1$]$. В приведенных документах речь, по всей видимости, шла о рекрутах, которых П.С. Салтыков 1 декабря 1710 г. отправил из Смоленска, сообщивший на следующий день А.Д. Меншикову, что в Санкт-Петербург он снарядил «из гварнизонных полков... 1000 человек солдат без ружья да рекрут 514 человек» [9, л. 308]. Первый из процитированных документов, на наш взгляд, очень важный - в нем впервые зафиксировано, что рекруты были отправлены в один из гарнизонов, где проходили обучение стрельбе.

В феврале 1711 г. полки, находившиеся в Риге и Лифляндии, были на случай диверсии 
шведов усилены 5459 рекрутами, а в Ригу было послано, кроме того, 8513 человек [22, c. 51-55]. Царским указом предыдущего года предписывалось набрать для гарнизона Риги 1200 человек, но, видимо, посчитали, что этого недостаточно, поэтому и направили рекрут, набранных в ходе «общего» набора. И вполне возможно, что в Риге оказались как раз те рекруты, которых первоначально предполагалось направить в Санкт-Петербург и которых ожидал Р.В. Брюс.

Очевидно, что рекруты в полки в первую очередь были необходимы для пополнения, но в то же время именно с этого года стала складываться практика, когда полки действующей армии пополнялись солдатами гарнизонных полков, а вместо них в крепости присылали рекрут.

Надо сказать, что такой подход был очень разумным - в гарнизонном полку рекрут не оказывался сразу в пекле боевых действий, а проходил первоначальную подготовку: учился солдатскому строю, навыкам обращения с оружием, караульной службе и многим другим вещам, необходимым воину. Все эти навыки рекруты, разумеется, получали и в полевых полках, и там этот процесс мог даже быть более быстрым, поскольку зачастую приходилось учиться непосредственно в боевых условиях, но это же могло приводить и к тому, что необученные солдаты порой оказывались в частях, вступавших в бой с неприятелем. В гарнизонах же обстановка была более спокойной.

Однако с распределением рекрут по гарнизонам в тот период постоянно возникали сложности. Хотя в целом обстановка на северо-западе была спокойной, у Петра I, возможно, имелись определенные опасения за оборону «новозавоеванных» территорий. Сложности были связаны с тем, что в результате кампании 1710 г. территория, занятая российскими войсками, увеличилась, поэтому количество частей, необходимых для их прикрытия, полков резко увеличилось. Кроме того, численность полков в тех частях, что действовала в Прибалтике, тоже сильно сократилась из-за эпидемии, поэтому пополнение требовалось всем. Это приводило к различным трениям.

Рижский обер-комендант Я.В. Полонский 25 июля 1711 г. сообщил из Риги, что новые полки он еще в полный комплект «ненарекрутовал» $[13$, л. 1]. Он же через два дня написал А.Д. Меншикову: «Указ вашей высококняжей светлости сего июля от 20 дня из Санкт-Питербурха писанный получил, в котором мне предложено о даче господину генерал-лейтенанту Боуру во обретающиеся команды его полки рекрут и лошадей и прочего, что он будет требовать. И на оное вашей высококняжой светлости всепокорнейше доношу. Прислал ко мне он господин генерал-лейтенант ведомость, что команды его драгунские и пехотные полки надобно в дополнку 4168 человек, а у меня толикого числа рекрут нет, понеже из губерний еще в указное число в присылке рекрут не сполна, а колико из которой губернии в привозе, из того числа учинено три полка, и что дано в Невский и в пехотные старые полки, отправлено в Пернов...» [14, л. 1].

То есть к июлю 1711 г. в Ригу еще не прибыли все те рекруты, которые были назначены туда, и у коменданта не было возможности укомплектовать полки в должной мере. При этом значительную часть людей ему необходимо было отпустить в полки действующей армии. И конфликт между Р.Х. Боуром и Я.В. Полонским продолжался. Рижский комендант выделил в полки Р.Х. Боура людей, однако генерал остался недоволен пополнением, посчитав, что в гарнизон комендант определил тех, кто лучше: «якобы из рекрут я выбрал в рижский гварнизон лутчих людей в новые полки, а его команды будто отдаю, выбрав плохих, о чем не знаю, кто ему сказал неправду...» $[15$, л. 1 об.]. Здесь также обратим внимание на словосочетание «в новые полки». Очевидно, что из рекрут в Риге формировали новые полки, которые и должны были составлять гарнизон крепости.

То же самое делали и в других крепостях Прибалтики. В июне 1711 г. в Ревель было определено два «рекрутских» полка, но прибыл только один [7, л. 1], а 27 августа ревельский комендант В.Н. Зотов доложил А.Д. Меншикову, что «рекрутскому полку, которой обретается при Ревеле, денежного окладу не учинено» $[8$, л. 2].

В Ингерманландии необходимости формирования новых полков не было, поэтому там стали пополнять те части, которые уже находились на той территории. Обер-комен- 
дант Р.В. Брюс 29 октября 1711 г. сообщил А.Д. Меншикову: «Московской губернии привозу подполковника Грузинцова рекрут принято у него по списку налицо 974 чел., и оные рекруты раскомандированы по полкам и к другим делам, так же после приему бежало и померло октября по 29 число сего 1711 г.:

Вяцкой драгунской полк - 644

в Тулицов - 71 чел.

В Толбугин -27 чел.

В Островской - 23 чел.

В Санкт-Питербурхе и на Ижоре отдано в каменщики - 145 чел.

Умре - 40 чел.

Бежало - 24 чел.» [12, л. 1].

Здесь необходимо отметить, что наибольшее число рекрут было направлено в Вятский драгунский полк, который не являлся гарнизонным. В 1710 г. он находился в Прибалтике (соответственно, понес значительные потери, отсюда и необходимость пополнения), осенью того года оставался в Ревеле [6, л. 1], а позже был назначен для похода в Финляндию. Еще часть людей направили не в полки, а на работы, связанные со строительством Санкт-Петербурга.

Кроме того, часть рекрут из наборов 1711 г. была отдана в артиллерию. 3 мая Е. Зыбин сообщил генерал-фельдцейхместеру Я.В. Брюсу, что 1000 человек рекрут взяты из полков и посланы в полевую армию к артиллерии [16, л. 339], а через месяц он же доложил, что «во артиллерии принято рекрут 2000 человек и в армию в посылке - 971 человек, да за болезнию непослано и бежало 29 человек» [16, л. 346]. Возможно, это были рекруты, которые прошли первоначальную подготовку именно в гарнизонных полках, после чего были направлены в артиллерию действующей армии.

Такой способ периодически использовали и позднее. В частности, в 1720 г., когда в Риге потребовалось пополнить комплект артиллеристов, для этого определили солдат из рижского гарнизона, которых, в свою очередь, заместили рекрутами [19, л. 125].

Также утвердился принцип, в соответствии с которым из рижского гарнизона солдат отправляли для пополнения полевой армии, а на их место Сенат присылал рекрут. К примеру, именно такое указание в августе
1715 г. получил рижский губернатор П.А. Голицын [23, с. 504].

Аналогичным путем в том же 1715 г. происходил процесс пополнения в корпусе, который действовал в Финляндии под командованием Ф.М. Апраксина. Правда, там был сильный некомплект, поэтому туда направили «рекрут и гарнизонных солдат» 1330 человек, из них «от камиссарства 420, из адмиралтейства 407, да по ведомости из Санкт-Питербурхской канцелярии в положенные на тое губернию армейские полки в тот корпус послано 303». А в губернии был послан указ о дополнительном наборе рекрут, которых тоже предполагалось сразу отправить в Финляндию [17, л. 23].

Отметим в связи с этим, что и рекруты, набранные в ходе наборов, объявленных в 1711 г., порой тоже сразу направлялись на пополнение армейских полков, в частности, 1000 человек были посланы для этого в Смоленск в марте 1712 г. [18, л. 26].

Результаты. Рекрутские наборы 1711 г. официально были объявлены в связи с войной против Турции и Прутским походом российской армии. Однако в это же время возникла необходимость пополнения гарнизонных полков крепостей северо-запада России, и рекрут стали направлять именно туда. Использовались для этого, по всей видимости, рекруты набора 1710 г. и первого набора 1711 года. И с этого времени стал складываться принцип, в соответствии с которым рекрута старались отправлять в гарнизонные полки, а затем, когда он осваивал азы военной службы, уже переводили в полевую армию или в артиллерию. Правда, нередко обстановка вынуждала направлять рекрут сразу в полки действующей армии. Основные трудности при распределении рекрут были связаны с тем, что пополнение в то время было необходимо буквально везде, и на этой почве между генералами и комендантами порой возникали трения.

Те документы, которые удалось обнаружить в архивах и которые впервые вводятся в научный оборот, позволяют сделать вывод, что гарнизоны Риги и Ревеля были в 1711 г. сформированы из полков, полностью укомплектованных рекрутами (естественно, кроме офицеров). Гарнизонные части крепостей Ингерманландии тоже пополняли рекрутами, и из донесений Р.В. Брюса к генерал-губернатору, 
выявленных в фонде Походной канцелярии А.Д. Меншикова, видно, как это происходило.

\section{СПИСОК ЛИТЕРАТУРЫ}

1. Анисимов, Е. В. Время петровских реформ /Е. В. Анисимов. - Л. : Лениздат, 1989. - 498 с.

2. Бабич, М. В. Потерявши... помним: к истории небоевых потерь частей, дислоцированных в Ингерманландии в 1711 году / М. В. Бабич, И. В. Бабич // Война и оружие. - СПб. : ВИМАИВиВС, 2012. Ч. 1. - C. 47-55.

3. Базарова, Т. А. «За кивиковою станицею лесами и болотами...». Первый русский комендант Выборга Г.П. Чернышев и борьба с «кивиками» / Т. А. Базарова // Санкт-Петербург и страны Северной Европы : материалы шестнадцатой ежегод. науч. конф. / ред. В. Н. Барышников, П. А. Кротов. СПб. : Изд-во РХГА, 2015. - С. 12-19.

4. Бескровный, Л. Г. Русская армия и флот в XVIII в. / Л. Г. Бескровный. - М. : Воениздат, 1958. $646 \mathrm{c}$.

5. Ведомости о выдаче жалованья и кормовых денег за работы у Адмиралтейства, октябрь 1712 г. // Российский государственный исторический архив военно-морского флота (РГА ВМФ). Ф. 176. - Оп. 1. - Д. 70. - Ч. 1. - Л. 21-69.

6. Донесение В. Н. Зотова А. Д. Меншикову 29 октября 1710 г. // Архив Санкт-Петербургского института истории РАН (Архив СПб ИИ РАН). Ф. 83. - Оп. 1. - Д. 3909. - 1 л.

7. Донесение В. Н. Зотова А. Д. Меншикову 30 июня 1711 г. // Архив СПб ИИ РАН. - Ф. 83. Оп. 1. - Д. 4429. - 1 л.

8. Донесение В. Н. Зотова А. Д. Меншикову 30 июня 1711 г. // Архив СПб ИИ РАН. - Ф. 83. Оп. 1. - Д. 4577. - 3 л.

9. Донесение П. С. Салтыкова А. Д. Меншикову 2 декабря 1710 г. // Архив СПб ИИ РАН. -Ф. 83. Оп. 2. - Д. 7. -340 л.

10. Донесение Р. В. Брюса А. Д. Меншикову 21 февраля 1711 г. // Архив СПб ИИ РАН. - Ф. 83. Оп. 1. - Д. 4206. - 1 л.

11. Донесение Р. В. Брюса А. Д. Меншикову 5 марта 1711 г. // Архив СПб ИИ РАН. - Ф. 83. Оп. 1. - Д. 4245. -1 л.

12. Донесение Р. В. Брюса А. Д. Меншикову 29 октября 1711 г. // Архив СПб ИИ РАН. -Ф. 83. Оп. 1. - Д. 4705. - 1 л.

13. Донесение Я. В. Полонского А. Д. Меншикову 25 июля 1711 г. // Архив СПб ИИ РАН. - Ф. 83.Оп. 1. - Д. 4246. - 1 л.

14. Донесение Я. В. Полонского А. Д. Меншикову 27 июля 1711 г. // Архив СПб ИИ РАН. -Ф. 83.Оп. 1. - Д. 4248. - 1 л.
15. Донесение Я. В. Полонского А. Д. Меншикову 31 июля 1711 г. // Архив СПб ИИ РАН. - Ф. 83.Оп. 1. - Д. $4231 .-1$ л.

16. Записная книга канцелярии генерал-фельдцейхмейстера, 1711 г. // Архив Военно-исторического музея артиллерии, инженерных войск и войск связи (Архив ВИМАИВиВС). - Ф. 2. - Оп. 1. Д. 131. -388 л.

17. Письмо И. Мусин-Пушкина Ф. М. Апраксину 18 августа 1715 г. // РГА ВМФ. -Ф. 233. - Оп. 1. Д. $92 .-374$ л.

18. Письмо П. Толстого Ф. М. Апраксину 7 марта 1712 г. // РГА ВМФ. - Ф. 233. - Оп. 1. Д. 34. -286 л.

19. Письмо Сената в канцелярию генерал-фельдщейхмейстера 23 мая 1720 г. // Архив ВИМАИВиВС. Ф. 2. -Оп. 2. - Д. 8. - 148 л.

20. Поливанов, К. М. Исторический очерк законов о рекрутской повинности от Петра I до 1810 г. / К. М. Поливанов. - СПб. : Тип. Фишера, 1850. - 94 с.

21. Полное собрание законов Российской империи. - СПб. : Тип. ІІ Отд-ния Собственной Его Императорского Величества Канцелярии, 1830. T. $4 .-890 \mathrm{c}$.

22. Резолюция Петра I на табели о солдатах и рекрутах, отправляемых в армию и в Ригу // Письма и бумаги императора Петра Великого. - Т. ХІ. Вып. 1. - М. : Изд-во АН СССР, 1962. - 609 с.

23. Сборник материалов и статей по истории Прибалтийского края. - Рига : Тип. А.И. Липинского, 1876. - Т. II. $-592 \mathrm{c}$.

24. Тихонов, В. А. Санкт-Петербургская ландмилиция: 1711-1719 гг. / В. А. Тихонов // Вестник Московского государственного областного университета. Серия: История и политические науки. 2008. - Вып. 1. - С. 14-21.

25. Тихонов, В. А. Рекрутская система комплектования русской армии в 1705-1710 гг. / В. А. Тихонов // Вестник Московского государственного областного университета. - 2012. - № 4. - С. 28-36.

\section{REFERENCES}

1. Anisimov E.V. Vremya petrovskih reform [The Time of Peter's Reforms]. Leningrad, Lenizdat, 1989. $498 \mathrm{p}$.

2. Babich M.V., Babich I.V. Poteryavshi... pomnim: k istorii neboevyh poter' chastej, dislocirovannyh v Ingermanlandii v 1711 godu [Having Lost... Remember: The History of Non-Combat Losses of Units Stationed in Ingermanland in 1711]. Vojna $i$ oruzhie [War and Weapons]. Saint Petersburg, VIMAIViVS, 2012, pt. 1, pp. 47-55.

3. Bazarova T.A. «Za kivikovoyu staniceyu lesami i bolotami...». Pervyj russkij komendant Vyborga 
G.P. Chernyshev i bor'ba s «kivikami» ["Behind the Civic Village, Forests and Swamps... The First Russian Commandant of Vyborg G.P. Chernyshev and the Fight Against "Kiviks"]. Sankt-Peterburg i strany Severnoj Evropy: materialy shestnadcatoj ezhegod. nauch. konf. [Saint Petersburg and the Nordic Countries: Materials of the Sixteenth Annual Scientific Conference]. Saint Petersburg, Izd-vo RKhGA, 2015, pp. 12-19.

4. Beskrovnyj L.G. Russkaya armiya iflot v XVIIIv. [The Russian Army and Navy in the XVIII Century]. Moscow, Voenizdat, 1958. 646 p.

5. Vedomosti o vydache zhalovan'ya i kormovyh deneg za raboty u Admiraltejstva, oktyabr' 1712 g. [On the Payment of Salaries and Feed Money for Work with the Admiralty, October 1712]. Rossijskij gosudarstvennyj istoricheskij arhiv voennomorskogo flota (RGA VMF) [Russian State Archive of the Navy], f. 176, inv. 1, d. 70, pt. 1, 1. 21-69.

6. Donesenie V.N. Zotova A.D. Menshikovu 29 oktyabrya 1710 g. [Report of V.N. Zotov to A.D. Menshikov of October 29, 1710]. Arhiv SanktPeterburgskogo instituta istorii RAN (Arkhiv SPb II RAN) [Archive of the Saint Petersburg Institute of History RAS], f. 83, inv. 1, d. 3909. 11.

7. Donesenie V.N. Zotova A.D. Menshikovu 30 iyunya 1711 g. [Report of V.N. Zotov to A.D. Menshikov of June 30, 1711]. Arkhiv SPb II RAN [Archive of the Saint Petersburg Institute of History RAS], f. 83, inv. 1, d. 4429. 11.

8. Donesenie V.N. Zotova A.D. Menshikovu 30 iyunya $1711 \mathrm{~g}$. [Report of V.N. Zotov to A.D. Menshikov of June 30, 1711]. Arkhiv SPb II RAN [Archive of the Saint Petersburg Institute of History RAS], f. 83, inv. 1, d. 4577. 31.

9. Donesenie P.S. Saltykova A.D. Menshikovu 2 dekabrya 1710 g. [Report of P.S. Saltykov to A.D. Menshikov of December 2, 1710]. Arkhiv SPb II RAN [Archive of the Saint Petersburg Institute of History RAS], f. 83, inv. 2, d. 7. 3401.

10. Donesenie R.V. Bryusa A.D. Menshikovu 21 fevralya 1711 g. [Report of R.V. Bruce to A.D. Menshikov of February 21, 1711]. Arkhiv SPb II RAN [Archive of the Saint Petersburg Institute of History RAS], f. 83, inv. 1, d. 4206. 11.

11. Donesenie R.V. Bryusa A.D. Menshikovu 5 marta 1711 g. [Report R.V. Bruce A.D. Menshikov of March 5, 1711]. Arkhiv SPb II RAN [Archive of the Saint Petersburg Institute of History RAS], f. 83, Inv. 1, d. 4245.11.

12. Donesenie R.V. Bryusa A.D. Menshikovu 29 oktyabrya $1711 \mathrm{~g}$. [Report of R.V. Bruce to A.D. Menshikov of October 29, 1711]. Arkhiv SPb II RAN [Archive of the Saint Petersburg Institute of History RAS], f. 83, inv. 1, d. 4705. 11.

13. Donesenie Ya.V. Polonskogo A.D. Menshikovu 25 iyulya 1711 g. [Report of Ya.V. Polonsky to
A.D. Menshikov of July 25, 1711]. Arkhiv SPb II RAN [Archive of the Saint Petersburg Institute of History RAS], f. 83, inv. 1, d. 4246. 11.

14. Donesenie Ya.V. Polonskogo A.D. Menshikovu 27 iyulya $1711 \mathrm{~g}$. [Report of Ya.V. Polonsky to A.D. Menshikov of July 27, 1711]. Arkhiv SPb II RAN [Archive of the Saint Petersburg Institute of History RAS], f. 83, inv. 1, D. 4248. 11.

15. Donesenie Ya.V. Polonskogo A.D. Menshikovu 31 iyulya $1711 \mathrm{~g}$. [Report of Ya.V. Polonsky to A.D. Menshikov of July 31, 1711]. Arkhiv SPb II RAN [Archive of the Saint Petersburg Institute of History RAS], f. 83, inv. 1, d. 4231. 11.

16. Zapisnaya kniga kancelyarii generalfel'dcejhmejstera, $1711 \mathrm{~g}$. [Notebook of the Chancellery of the Field-General of the Army, 1711]. Arhiv Voenno-istoricheskogo muzeya artillerii, inzhenernyh vojsk $i$ vojsk svyazi (Arkhiv VIMAIViVS) [Archive of the Military Historical Museum of Artillery, Engineering Troops and Signal Corps], f. 2, inv. 1, d. 131.3881 .

17. Pis'mo I. Musin-Pushkina F.M. Apraksinu 18 avgusta $1715 \mathrm{~g}$. [Letter from I. Musin-Pushkin to F.M. Apraksin of August 18, 1715]. Arkhiv VIMAIViVS [Archive of the Military Historical Museum of Artillery, Engineering Troops and Signal Corps], f. 233, inv. 1, d. 92.3741 .

18. Pis'mo P. Tolstogo F.M. Apraksinu 7 marta 1712 g. [Letter of P. Tolstoy to F.M. Apraksin of March 7, 1712]. Arkhiv VIMAIViVS [Archive of the Military Historical Museum of Artillery, Engineering Troops and Signal Corps], f. 233, inv. 1, d. 34. 2861.

19. Pis'mo Senata v kancelyariyu generalfel'dcejhmejstera 23 maya $1720 \mathrm{~g}$. [Letter from the Senate to the Office of the Field-General-Mayor of May 23, 1720]. Arkhiv VIMAIViVS [Archive of the Military Historical Museum of Artillery, Engineering Troops and Signal Corps], f. 2, inv. 2, d. 8.1481 .

20. Polivanov K.M. Istoricheskij ocherk zakonov o rekrutskoj povinnosti ot Petra I do $1810 \mathrm{~g}$. [The Historical Outline of the Laws on Recruitment Service from Peter I to 1810]. Saint Petersburg, Tipografiya Fishera, $1850.94 \mathrm{p}$.

21. Polnoe sobranie zakonov Rossijskoj imperii [The Complete Collection of Laws of the Russian Empire]. Saint Petersburg, Tipografiya II Otdeleniya Sobstvennoy Ego Imperatorskogo Velichestva Kantselyarii, 1830, vol. 4. 890 p.

22. Rezolyuciya Petra I na tabeli o soldatah i rekrutah, otpravlyaemyh $\mathrm{v}$ armiyu i v Rigu [The Resolution of Peter I on the Table of Soldiers and Recruits Sent to the Army and to Riga]. Pis'ma $i$ bumagi imperatora Petra Velikogo [Letters and Papers of Emperor Peter the Great], vol. XI, iss. 1. Moscow, Izd-vo AN SSSR, 1962. 609 p. 


\section{ВООРУЖЕННЫЕ СИЛЫ И ВОЕННЫЕ ДЕЙСТВИЯ}

23. Sbornik materialov i statej po istorii Pribaltijskogo kraya [A Collection of Materials and Articles on the History of the Baltic Region]. Riga, Tipografiya A.I. Lipinskogo, 1876, vol. II. 592 p.

24. Tihonov V.A. Sankt-Peterburgskaya landmiliciya: 1711-1719 gg. [Petersburg Land Police: 17111719]. Vestnik Moskovskogo gosudarstvennogo oblastnogo universiteta. Seriya: Istoriya $i$ politicheskie nauki [Bulletin of Moscow State
Regional University. Series: History and Political Science], 2008, iss. 1, pp. 14-21.

25. Tihonov V.A. Rekrutskaya sistema komplektovaniya russkoj armii v 1705-1710 gg. [Recruitment System for the Acquisition of the Russian Army in 1705-1710]. Vestnik Moskovskogo gosudarstvennogo oblastnogo universiteta [Bulletin of Moscow State Regional University], 2012, no. 4, pp. 28-36.

\section{Information About the Author}

Nikolai R. Slavnitsky, Candidate of Sciences (History), Chief Researcher, State Museum of the History of Saint Petersburg, Peter and Paul Fortress, 3, 197046 Saint Petersburg, Russian Federation, slavnitski@bk.ru, https://orcid.org/0000-0002-1590-9423

\section{Информация об авторе}

Николай Равильевич Славнитский, кандидат исторических наук, главный научный сотрудник, Государственный музей истории Санкт-Петербурга, Петропавловская крепость, 3, 197046 г. Санкт-Петербург, Российская Федерация, slavnitski@bk.ru, https://orcid.org/0000-0002-1590-9423 